\title{
Congenital diaphragmatic hernia
}

INSERM

\section{Source}

INSERM. (1999). Orphanet: an online rare disease and orphan drug data base. Congenital diaphragmatic hernia. ORPHA:2140

Congenital diaphragmatic hernia $(C D H)$ is a posterolateral defect of the diaphragm that allows passage of abdominal viscera into the thorax, leading to respiratory insufficiency and persistent pulmonary hypertension with high mortality. 